Chapter 12

\title{
Assessment of Postoperative Venous Thromboembolism Risk in Body Sculpting Procedures
}

\author{
Alexandro Aguilera Salgado, \\ Johnatan Figueroa Padilla and José Cortés Arreguín
}

Additional information is available at the end of the chapter

http://dx.doi.org/10.5772/64841

\begin{abstract}
Venous thromboembolism is a common complication following surgical procedures. It is imperative for us to identify which risks factors are present in our patients, not only because body sculpting procedures are elective, but also to help us perform an individualized assignment of venous thromboembolism risk. Once we have identified the risk, we can select a method of venous thromboembolism prophylaxis based on the guidelines by the American College of Chest Physicians and the other individualized risk scales presented in this chapter. Our main goal is to keep as low as possible the incidence of venous thromboembolism and its complications.
\end{abstract}

Keywords: venous, thromboembolism, risk, body, sculpting, postoperative

\section{Introduction}

Body sculpting procedures can be associated to postoperative venous thromboembolism in patients with certain characteristics. This entity can lead to fatal consequences, like pulmonary embolism and death, that is why it is important for us to clearly assess the risk for each individual in the preoperative setting, in order to establish certain procedures and prophylaxis, which may help us lower or diminish these risks to the minimum. Given these are elective procedures, it should beour main concern that our patients are well prepared before the surgery with a complete preoperatory analysis of the risks both the patient and the surgery per se represent. 


\section{Background}

Venous thromboembolism represents a wide spectrum of disease, ranging from deep venous thrombosis to pulmonary embolism, a very relevant complication following body sculpting procedures, especially those who combine two or three procedures in one surgery. Some studies have reported that each year 350,000-600,000 Americans suffer from deep venous thrombosis and pulmonary embolism and that at least 100,000 deaths are directly or indirectly related to venous thromboembolism [1]. These numbers represent the incidence in general population, not specifically following body sculpting procedures, nevertheless some studies in the last few years have discussed this matter.

Some data collected from a worldwide survey among certificated plastic surgeons revealed pulmonary embolism as the main cause of death following a liposuction, which represented the $23 \%$ of all deaths [2]. Another study that included all the procedures performed inside an operating room reported that $63.6 \%$ of the postoperative deaths were secondary to thromboembolism [3]. Considering large-volume liposuction procedures, Albin and de Campo reported an incidence of venous thromboembolism of $1.7 \%$ in patients where the aspirated volume was larger than $5 \mathrm{~L}$ [4]. Grazer and Goldwyn cited a 1.9\% incidence of venous thromboembolism in a series of abdominoplasty patients [5]. Finally, in combined procedures and with longer surgical times as belt lipectomies, there is a higher incidence of thromboembolism, as reported by Aly and colleagues with a $9.4 \%$ incidence in this group of patients [6].

Given these high rates of mortality following venous thromboembolism complicated with pulmonary embolism after body sculpting procedures, it should be logic for us to think that the surgeons performing these procedures would establish a prophylaxis protocol in all their patients in order to lower the risk of the development of venous thromboembolism. Nevertheless, some worldwide studies have reported that only $43.7 \%$ of the surgeons performing liposuction procedures and $60.8 \%$ of the surgeons performing a combined body sculpting procedure use thromboembolism prophylaxis [7]. This can be secondary to the belief that venous thromboembolism has a low incidence, or because of the fear to have bleeding complications and postoperative hematomas, with dehiscence of wound and infection.

\section{Risk factors}

In order to develop a venous thromboembolism, two variables must be present interacting between them: first, the individual patient's risk factors which cannot be modified and are usually permanent and second, the circumstances surrounding the time and place where the thromboembolism occurs, being transient in nature, with the possibility to be modified most of the times.

Risk factors inherent to the patient include age, active malignancy, history of venous thromboembolism, other chronic diseases such as heart or respiratory failure, spinal cord injury, multiple trauma, myocardial infarction, congenital or acquired coagulation disorders (antith- 
rombin deficiency, Protein C and Protein S deficiency, elevated coagulation factors), hormone replacement therapy, and oral contraception. Critically ill patients receiving intensive care are also considered to be a population at risk for developing venous thromboembolism.

According to the British Thoracic Society, patient risk factors are traditionally classified into major and minor categories (Table 1) [8]. Remember, these predisposing factors cannot be modified, so the seldom presence of them justifies the use of prophylaxis. The important thing here is not only to be able to identify those factors, but also to assess the overall risk of venous thromboembolism in each patient and to establish the appropriate prophylaxis regimen in each case [9].

\begin{tabular}{ll}
\hline Major risk factors $(\mathbf{R R}=\mathbf{5 - 2 0})$ & Minor risk factors $(\mathbf{R R} \mathbf{~ 2 - 4 )}$ \\
\hline $\begin{array}{l}\text { Postoperative state: major abdominal/pelvic } \\
\text { surgery, hip/knee joint replacement, }\end{array}$ & $\begin{array}{l}\text { Cardiovascular: congenital heart disease, heart failure, hypertension, } \\
\text { superficial venous thrombosis, central venous catheter }\end{array}$ \\
$\begin{array}{l}\text { postoperative intensive care } \\
\text { Obstetrics: late pregnancy, caesarian section, } \\
\text { puerperium }\end{array}$ & $\begin{array}{l}\text { Humoral: estrogen use: oral contraception, hormone replacement } \\
\text { therapy }\end{array}$ \\
$\begin{array}{l}\text { Lower limb affections: fractures, extensive } \\
\text { varicosities }\end{array}$ & $\begin{array}{l}\text { Miscellaneous: chronic obstructive lung disease, neurological } \\
\text { impairment, latent malignancy, thrombotic defects, long-distance } \\
\text { Malignancies: abdominal/pelvic, advanced/ }\end{array}$ \\
$\begin{array}{l}\text { travel in the sitting position, obesity } \\
\text { metastatic stage }\end{array}$ & $\begin{array}{l}\text { Other: inflammatory bowel disease, nephrotic syndrome, chronic } \\
\text { dialysis, myeloproliferative disease, paroxysmal nocturnal } \\
\text { himited mobility: hospitalization geriatric care }\end{array}$ \\
& \\
$\begin{array}{l}\text { Miscellaneous: history of previous venous } \\
\text { thromboembolism }\end{array}$
\end{tabular}

Table 1. Risk factor of venous thromboembolism, according to the British Thoracic Society [8].

Besides these risk factors inherent to the patient, the surgical procedure per se represents also a risk factor to the patient. General anesthesia, supine position as well as immobilization produce blood stasis. Decreased venous return also diminishes the clearance of activated clotting factors, which in turn augments the hypercoagulable state. Finally, intimal injury is secondary to venous traction and to the vasodilatory effect of anesthesia, which favors platelets deposits in the sites of vascular injury, initiating the coagulation cascade.

\section{Natural history of venous thromboembolism}

As described earlier in this chapter, venous thromboembolism includes various stages of complex developments, which can be fatal as they lead the patient to a pulmonary embolism. Regardless of the patient's risk factors, the surgery alone is one of the most important risk 
factors we will face. During surgery, the patient will be prone to stasis, hypercoagulability and endothelial injury, which in turn can explain how $50 \%$ of deep vein thrombosis associated with surgery start intraoperatively. The first affected veins will be the most distal ones, located at the calf region. Of these affected cases, approximately $50 \%$ may resolve spontaneously within $72 \mathrm{~h}$ with the use of adequate venous thromboprophylaxis, which will help in the lysis of thrombi and prevent the formation of new ones. When the deep vein thrombosis is isolated to the calf, it will rarely cause leg symptoms or clinically important pulmonary embolisms [10].

Of the untreated symptomatic calf deep vein thromboses, approximately $25 \%$ will extend to more proximal veins as late as 1 week after the surgery, and subsequently break free to cause pulmonary embolism in the late stages. Each of these stages may or may not be associated with symptoms. The development of symptoms depends on the extent of thrombosis, the adequacy of collateral vessels, and the severity of associated vascular occlusion and inflammation.

In those cases where the thrombi moves in a more proximal direction toward the inguinal region and it is symptomatic but without chest symptoms, approximately $50 \%$ of the patients will have a pulmonary embolism on lung scan [11]. From day 3 to day 7 of the postoperative period the patient will be at the highest risk of the development of fatal pulmonary embolism, being fatal around $10 \%$ of symptomatic pulmonary embolisms within one hour of first symptoms. Furthermore, the patient will be at the highest risk of developing symptomatic venous thromboembolism within 2 weeks of surgery, but that risk will remain elevated for 2 3 months [12].

The severity of acute pulmonary embolism is determined primarily by its hemodynamic impact, presenting as sudden pulmonary hypertension. In healthy patients, it is known that a pulmonary bed obstruction of $30-50 \%$ is needed in order to develop pulmonary hypertension [13]. In the other hand, patients with a previous history of lung or heart disease will develop pulmonary hypertension with even a minor obstruction in the pulmonary circulation. The acutely developing pulmonary hypertension in pulmonary embolism leads to an increase in right ventricular after load, morphologically presenting as right ventricular dilation and may eventually cause right heart failure, which results in decreasing of left ventricular filling, and deteriorated diastolic left ventricular function due to right ventricular dilation. After a diagnosed pulmonary embolism, $50 \%$ of patients have right ventricular dysfunction on echocardiography. These events can lead to a fall in blood pressure and present as syncope, hypotension or carcinogenic shock, resulting in sudden death [14]. After a symptomatic deep vein thrombosis, there is an approximately $10 \%$ cumulative incidence of severe postthrombotic syndrome after 5 years.

\section{Assessment of postoperative venous thromboembolism risk}

In each patient to undergo a surgical body contouring procedure should be implemented a strategic scheme of risk assessment, planning and establish measures to reduce morbidity and mortality [15]. We must identify the preventive management of hypercoagulable states. Risk stratification will allow us to make good decisions, especially in patients at high risk. 
Over the past two decades, thromboprophylaxis has taken greater importance, given the increase in the number of surgical procedures performed in the body contour area. Because of this, there have been designed, applied, and evaluated various risk models for venous thromboembolism [16-19]. The most widely known and validated model is the one developed by Caprini et al.

This model was initially published in 1991 [20], which with the passage of time has been modified and refined. In the published version of 2005, plastic and reconstructive surgery patients were included, predicting the risk of venous thromboembolism within 30 or 60 days (Figure 1) [21]. As a result of these validation studies, strata have been identified to report level of risk and response to prophylaxis based on risk level [22-23].

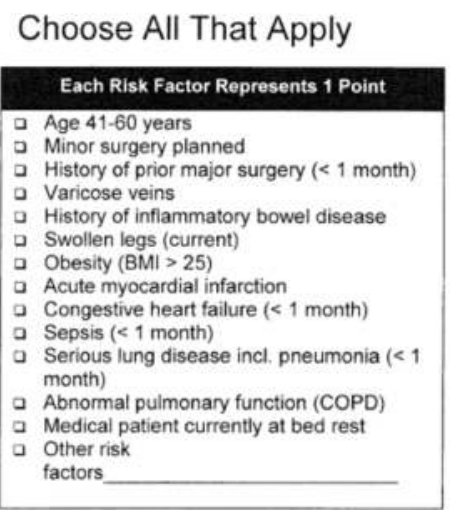

\section{Each Risk Factor Represents 3 Points}

a Age over 75 years

a History of DVT/PE

a Family history of thrombosis*

- Positive factor $V$ Leiden

a Positive prothrombin 20210A

a Elevated serum homocysteine

a Positive lupus anticoagulant

a Elevated anticardiolipin antibodies

a Heparin-induced thrombocytopenia (HIT)

a Other congenital or acquired thrombophilia If yes:

Type

"most frequently missed risk factor
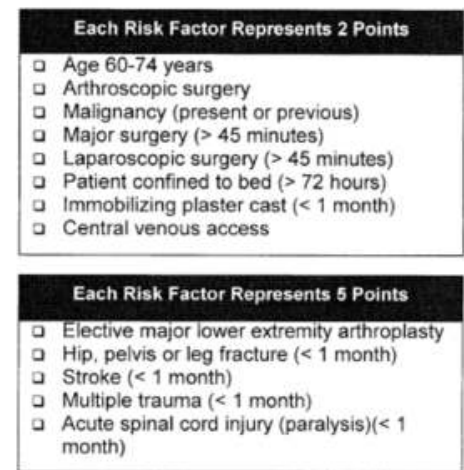

For Women Only (Each Ropresents 1 Point)

- Oral contraceptives or hormone replacement therapy

a Pregnancy or postpartum ( $<1$ month)

a History of unexplained stillborn infant, recurrent spontaneous abortion $(\geq 3)$. premature birth with toxemia or growthrestricted infant

\section{Total Risk Factor Score}

Figure 1. The 2005 Caprini risk assessment model. COPD, chronic obstructive pulmonary disease; DVT, deep venous thrombosis; PE, pulmonary embolism. Caprini, Thrombosis risk assessment as a guide to quality patient care. 2005.

The most recent version of the Caprini Risk Assessment Model was published in 2010 (Figure 2) [24]. When compared with the 2005 Risk Assessment Model, the 2010 Risk Assessment Model has four distinct, data-driven changes, including addition of new risk factors or reweighting of old risk factors. Some studies have shown that Caprini 2010 model gives an altered estimate of the risk of thromboembolism with consequent inappropriate application of preventive measures, so what right now the evidence does not support is its use in patient stratification until it is validated more widely [25]. 


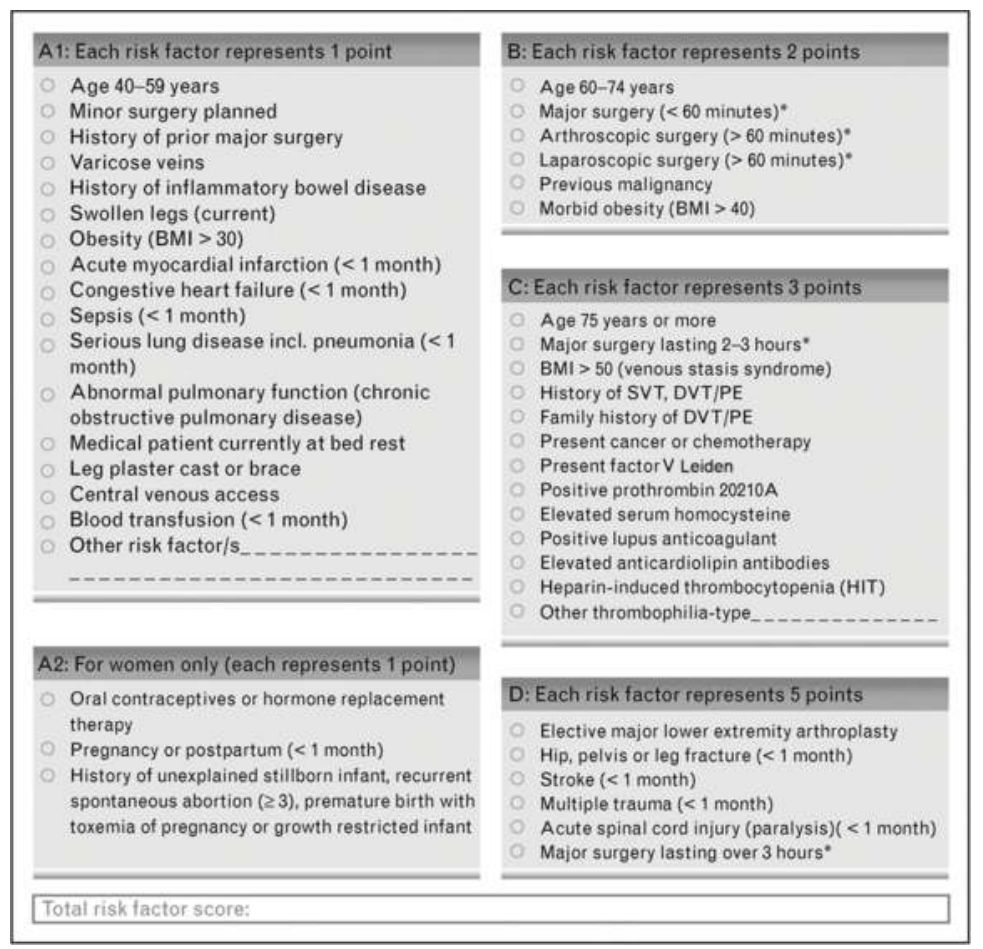

Figure 2. The 2010 Caprini risk assessment model. Risk assessment as a guide to thrombosis prophylaxis. Curr Opin Pulm Med. 2010.

The 2012 American College of Chest Physicians guidelines note that at any level of 2005 Caprini score, plastic and reconstructive surgery patients are at decreased risk of venous thromboembolism compared with patients undergoing abdominal and pelvic surgery [26]. Prior validation studies of the 2005 Caprini score in plastic and reconstructive surgery patients [27] and the head and neck surgery population [28] showed that $70-80 \%$ of patients in the overall population are classified as lower risk (2005 Caprini scores of 3-4 or 5-6). Thus, only a small proportion of patients fall into the highest risk strata.

We recommend that all plastic and reconstructive surgery patients should be risk-stratified for perioperative venous thromboembolism risk using a 2005 Caprini score and that surgeons consider chemoprophylaxis on a case-by-case basis in patients with Caprini score $>8$.

\section{Thrombosis and venous thromboembolism prophylaxis}

Venous stasis is a recognized venous thromboembolism risk factor. Stasis, along with hypercoagulability and intimal damage, constitutes the central tenets of Virchow's triad for throm- 
bosis. Stasis also promotes venous dilation, resulting in intimal microtears. This exposes subendothelial collagen and initiates the clotting cascade. Venous dilation is known to predict deep venous thrombosis in other surgical subspecialties [29].

In recent years there has been consensus in plastic surgery looking forward to find the best available evidence on prevention, taking into account the best scientific articles of all specialties related to venous thrombosis. The most important aspects for a surgeon about this issue are enlisted.

\section{Type of anesthesia}

General anesthesia, paralysis, or both eliminate calf muscle pump action in the lower extremities. The calf muscle pump propels venous blood cranially and, in concert with the venous valve system, mitigates venous stasis and venous dilation. A recent study of 200 patients having elective plastic surgery under spontaneous breathing, avoid gas, face up, extremities mobile (SAFE) anesthesia with postoperative duplex ultrasound screening showed an asymptomatic deep venous thrombosis rate of $0.5 \%$. This rate is similar to symptomatic venous thromboembolism rates among low-risk (2005 Caprini score of 3 or 4) plastic surgery in patients undergoing surgery under general anesthesia [21,30]. The recommendation on this issue is limited by the fact that some operations require general anesthesia, and thus this recommendation is not applicable to all patients.

Pannucci et al. [25] recommend using non-general anesthesia when appropriate. When possible, consideration should be given to using monitored anesthesia care, local anesthesia with sedation, or neuraxial anesthesia instead of general anesthesia with a grade $1 \mathrm{C}$ level of evidence (Table 2) [31].

\begin{tabular}{|c|c|c|c|c|}
\hline Grade & Description & $\begin{array}{l}\text { Benefit vs risk and } \\
\text { burdens }\end{array}$ & $\begin{array}{l}\text { Quality of supporting } \\
\text { evidence }\end{array}$ & Implications \\
\hline $1 \mathrm{~A}$ & $\begin{array}{l}\text { Strong } \\
\text { recommendation, } \\
\text { high-quality } \\
\text { evidence }\end{array}$ & $\begin{array}{l}\text { Benefits clearly } \\
\text { outweigh risks and } \\
\text { burdens, } \\
\text { or vice versa }\end{array}$ & $\begin{array}{l}\text { RCTs without important } \\
\text { limitations or } \\
\text { overwhelming evidence } \\
\text { from observational } \\
\text { studies }\end{array}$ & $\begin{array}{l}\text { Strong recommendation } \\
\text { and can apply to most } \\
\text { patients in most } \\
\text { circumstances } \\
\text { without reservation }\end{array}$ \\
\hline 1B & $\begin{array}{l}\text { Strong } \\
\text { recommendation, } \\
\text { moderate-quality } \\
\text { evidence }\end{array}$ & $\begin{array}{l}\text { Benefits clearly } \\
\text { outweigh risks and } \\
\text { burdens, } \\
\text { or vice versa }\end{array}$ & $\begin{array}{l}\text { RCTs with important } \\
\text { limitations or } \\
\text { exceptionally strong } \\
\text { evidence from } \\
\text { observational studies }\end{array}$ & $\begin{array}{l}\text { Strong recommendation } \\
\text { and can apply to most } \\
\text { patients in most } \\
\text { circumstances } \\
\text { without reservation }\end{array}$ \\
\hline $1 \mathrm{C}$ & $\begin{array}{l}\text { Strong } \\
\text { recommendation } \\
\text { low- or very } \\
\text { low-quality }\end{array}$ & $\begin{array}{l}\text { Benefits clearly } \\
\text { outweigh risks and } \\
\text { burdens, } \\
\text { or vice versa }\end{array}$ & $\begin{array}{l}\text { Observational studies or } \\
\text { case series }\end{array}$ & $\begin{array}{l}\text { Strong recommendation } \\
\text { but may change when } \\
\text { higher quality evidence } \\
\text { becomes available }\end{array}$ \\
\hline
\end{tabular}




\begin{tabular}{|c|c|c|c|c|}
\hline Grade & Description & $\begin{array}{l}\text { Benefit vs risk and } \\
\text { burdens }\end{array}$ & $\begin{array}{l}\text { Quality of supporting } \\
\text { evidence }\end{array}$ & Implications \\
\hline & evidence & & & \\
\hline $2 \mathrm{~A}$ & $\begin{array}{l}\text { Weak } \\
\text { recommendation, } \\
\text { high-quality evidence }\end{array}$ & $\begin{array}{l}\text { Benefits closely } \\
\text { balanced with risks } \\
\text { and burden }\end{array}$ & $\begin{array}{l}\text { RCTs without important } \\
\text { limitations or } \\
\text { overwhelming evidence } \\
\text { from observational } \\
\text { studies }\end{array}$ & $\begin{array}{l}\text { Weak recommendation, } \\
\text { best action may differ } \\
\text { depending on circumstances } \\
\text { or patient's } \\
\text { or societal values }\end{array}$ \\
\hline $2 B$ & $\begin{array}{l}\text { Strong } \\
\text { recommendation } \\
\text { moderate-quality } \\
\text { evidence }\end{array}$ & $\begin{array}{l}\text { Benefits closely } \\
\text { balanced with risks } \\
\text { and burden }\end{array}$ & $\begin{array}{l}\text { RCTs with important } \\
\text { limitations or } \\
\text { exceptionally strong } \\
\text { evidence from } \\
\text { observational studies }\end{array}$ & $\begin{array}{l}\text { Weak recommendation, } \\
\text { best action may differ } \\
\text { depending on circumstances } \\
\text { or patient's } \\
\text { or societal values }\end{array}$ \\
\hline $2 C$ & $\begin{array}{l}\text { Weak } \\
\text { recommendation } \\
\text { low- or very } \\
\text { low-quality } \\
\text { evidence }\end{array}$ & $\begin{array}{l}\text { Uncertainty in the } \\
\text { estimated of benefits } \\
\text { risks, and burden; } \\
\text { benefits, risk, and } \\
\text { burden may be closely } \\
\text { balanced }\end{array}$ & $\begin{array}{l}\text { Observational studies or } \\
\text { case series }\end{array}$ & $\begin{array}{l}\text { Very weak } \\
\text { recommendation; other } \\
\text { alternatives may } \\
\text { be equally reasonable }\end{array}$ \\
\hline
\end{tabular}

Reproduced from Guyatt et al. [31].

Table 2. RCTs (randomized controlled trials).

\section{Use of pneumatic compression and/or elastic stockings}

Elastic stockings (also known as graduated compression stockings) may preferentially shunt venous blood from the superficial to the deep venous system through perforating veins.

Shunting augments the volume and velocity within the deep venous system, theoretically decreasing stasis and the likelihood of thrombosis [32, 33]. Elastic stockings are significantly more effective than no stockings for both deep venous thrombosis and pulmonary embolus prevention in general and orthopedic surgery patients [33].

Intermittent pneumatic compression devices (also known as sequential compression devices) work by means of multiple mechanisms. The sequential compression serially "pumps" blood from caudal to cranial, using the venous valve system to facilitate egress of venous blood and minimizing venous stasis and venous dilation. Intermittent pneumatic compression also stimulates the body's endogenous fibrinolytic mechanism. Blood samples taken distant from the intermittent pneumatic compression site show stimulation of bloodborne fibrinolytic activity when intermittent pneumatic compression is applied. Thus, intermittent pneumatic compression applied to a single leg can provide deep venous thrombosis risk reduction by means of both a direct and an indirect mechanism [34]. A meta-analysis by Ho and Tan shows that intermittent pneumatic compression is superior to elastic compression stockings for deep venous thrombosis risk reduction [35]. 
The latest recommendations about this are using intermittent pneumatic compression to prevent perioperative venous thromboembolism events in plastic surgery patients [25]. In the absence of rigorous publications in plastic surgery, this recommendation was derived largely from meta-analyses in other specialties (Grade 1B). Same recommendation applies for elastic compression stockings, but most meta-analyses recommend the intermittent pneumatic compression over the compression stockings (Grade 1B).

\section{Effectiveness of chemoprophylaxis and bleeding risk}

When we refer to chemoprophylaxis, we are referring to unfractionated heparin or low molecular weight heparin provided at prophylactic doses. The 2012 American College of Chest Physicians guidelines on deep venous thrombosis and pulmonary embolus prevention for nonorthopedic surgical patients do not recommend low-dose aspirin as first-line venous thromboembolism prophylaxis; as a result, experts do not recommend aspirin as first-line venous thromboembolism prophylaxis for plastic surgery patients.

Low-dose aspirin is recommended as prophylaxis only when unfractionated heparin and low molecular weight heparin are contraindicated or not available [26]. Only one study that compared aspirin to low molecular weight heparin in 505 free flap patients showed no difference in postoperative venous thromboembolism or bleeding. However, based on a relative paucity of data, we could not make recommendations specific to plastic surgery patients [36].

The oral factor Xa inhibitor "apixaban" has U.S. Food and Drug Administration approval for stroke reduction in nonvalvular atrial fibrillation, deep venous thrombosis, and pulmonary embolism prophylaxis after adult hip or knee replacement [37]. The oral factor Xa inhibitor "rivaroxaban" has U.S. Food and Drug Administration approval for stroke prophylaxis in nonvalvular atrial fibrillation, deep venous thrombosis and pulmonary embolism prophylaxis after adult hip and knee replacement, and for treatment of deep venous thrombosis or pulmonary embolism events [38]. Neither drug is U.S. Food and Drug Administration approved for venous thromboembolism prophylaxis in the general surgery population.

Prior studies of patients undergoing abdominal and pelvic surgery have shown significant venous thromboembolism risk reduction with a combination of chemoprophylaxis plus intermittent pneumatic compression versus intermittent pneumatic compression alone [39, 40]. Meta-analyses in high-risk surgical patients, including a Cochrane review, showed that combination prophylaxis significantly decreased the risk of symptomatic pulmonary embolism and symptomatic deep venous thrombosis [41, 42].

Population level data in plastic surgery did not show a significant venous thromboembolism risk reduction with chemoprophylaxis. In addition, there was evidence of harm in the overall population with increased rates of reoperative hematoma. These findings, paired with the known low venous thromboembolism risk among many plastic surgery patients, suggest that chemoprophylaxis should not routinely be provided to all plastic surgery patients [21]. 
Bleeding risk with chemoprophylaxis did not show a clear trend in the risk-stratified analysis. As 2005 Caprini score increased, estimates became less precise, as evidenced by the wider confidence intervals. This finding has face validity, as the 2005 Caprini score has been validated to predict risk of venous thromboembolism but not risk of bleeding. In other studies, plastic surgery patients with 2005 Caprini scores of $>8$ had a 60 -day venous thromboembolism rate of $11.3 \%$ when no prophylaxis was provided, whereas chemoprophylaxis is reported to decrease 60-day venous thromboembolism risk by $50 \%$ [43].

When plastic surgeons choose to use chemoprophylaxis, there are minimal data to support an evidence-based recommendation for the appropriate duration of chemoprophylaxis. However, as length of inpatient stay was variable, patients received different durations of chemoprophylaxis. Prior work in plastic surgery has shown that among super high-risk patients (2005 Caprini score >8), venous thromboembolism events occur with the same frequency at postoperative weeks 3-8 as they do at weeks 1-2. The expert panel of 2015 does not recommend adding routine chemoprophylaxis to intermittent pneumatic compression for venous thromboembolism prophylaxis in the general non-risk-stratified plastic surgery population. They recommend that all plastic and reconstructive surgery patients should be risk-stratified for perioperative venous thromboembolism risk using a 2005 Caprini score and that surgeons consider chemoprophylaxis on a case-by-case basis in patients with Caprini score $>8$ (Grade $1 \mathrm{C}$ ).

\section{Timing of chemoprophylaxis administration}

Ultimately, the surgeon must balance the relative risks of venous thromboembolism with chemoprophylaxis-associated venous thromboembolism risk reduction and bleeding risk in their decision to provide chemoprophylaxis. Davison and Massoumi [44] said: "An hematoma is a medical stress, an inconvenience, an embarrassment, or an additional procedure, but rarely does it kill a patient. Thromboembolism that progresses to a pulmonary embolism kills the patient $50 \%$ of the time." The classic teaching has been that deep venous thrombosis forms in the operating table, in response to induction of hypotension and vasodilation. Thus, initiation of preoperative mechanical and chemoprophylaxis are conceptually appealing for venous thromboembolism risk reduction.

The 1999 American Society of Plastic Surgeons consensus statement on deep venous thrombosis prophylaxis by McDevitt recommended that "thromboprophylaxis for the surgical patient should begin before the operative procedure. All such measures are directed toward enhancing venous flow, decreasing serum thrombogenic factors, and stabilizing the vascular endothelium." As such, low molecular weight heparin administered at least $2 \mathrm{~h}$ before surgery was recommended for moderate-and high-risk patients, "when dissection will not be extensive" [45]. However, there are insufficient data to recommend preoperative over postoperative chemoprophylaxis for venous thromboembolism prevention in the non-risk-stratified plastic surgery population. Also preoperative chemoprophylaxis was not associated with an increased risk of hematoma compared to postoperative chemoprophylaxis in the non-riskstratified plastic surgery population (Grade 2C). 


\section{Unfractionated heparin versus low molecular weight heparin}

Many studies had very wide confidence intervals, and their aggregate effect may have skewed data for this clinical question. There is a meta-analysis that included 16 randomized controlled trials and nearly 13,000 patients showed no significant difference in postoperative venous thromboembolism, major bleeding, or minor bleeding for cancer patients who received preoperative unfractionated heparin versus low molecular weight heparin [46].

In a single-center study of breast surgery patients, low molecular weight heparin was suggested to have a higher risk of preoperative hematoma compared with unfractionated heparin [47]. The data presented in the various studies are ambiguous, but there are some suggestions based on exhaustive reviews. In conclusion, neither subtype of heparin (low molecular weight or unfractionated) conferred an advantage over mechanical prophylaxis alone for venous thromboembolism risk reduction in the non-risk-stratified plastic surgery population. Low molecular weight but not unfractionated heparin conferred an increased risk of reoperative hematoma in the non-risk-stratified plastic surgery population [25] (Grade 2C).

\section{Effectiveness and bleeding risk for chemoprophylaxis by surgery type}

There are special situations in plastic surgery, for example, complex reconstructions with free flaps for breast or head and neck cancer. An analysis of transverse rectus abdominis musculocutaneous (TRAM) flap patients was unable to separate pedicled TRAM flap from free TRAM flap breast reconstructions. Thus, these results are difficult for interpretation, as the extent of surgery, duration of surgery, and tightness of abdominal wall closure are substantially different between the two groups [48-50].

\begin{tabular}{|c|c|c|c|}
\hline Patient group & Intervention & Recommended? & Grade \\
\hline All plastic surgery patients & Non-general anesthesia & Yes & $1 \mathrm{C}$ \\
\hline All plastic surgery patients & Intermittent pneumatic compression & Yes & $1 \mathrm{~B}$ \\
\hline All plastic surgery patients & Chemoprophylaxis & No & $1 \mathrm{C}$ \\
\hline All plastic surgery patients & Preoperative risk stratification (Caprini) & Yes & $1 \mathrm{C}$ \\
\hline Caprini score $>8$ & Chemoprophylaxis & Individualized & $1 \mathrm{C}$ \\
\hline All plastic surgery patients & $\begin{array}{l}\text { Preoperative vs. postoperative } \\
\text { chemoprophylaxis }\end{array}$ & $\begin{array}{l}\text { Insufficient data for } \\
\text { recommendation }\end{array}$ & $2 \mathrm{C}$ \\
\hline All plastic surgery patients & $\begin{array}{l}\text { Low molecular weight vs. } \\
\text { unfractioned heparin }\end{array}$ & $\begin{array}{l}\text { No recommendation on } \\
\text { medication type }\end{array}$ & $2 \mathrm{C}$ \\
\hline $\begin{array}{l}\text { TRAM, body contouring, } \\
\text { general head and neck }\end{array}$ & Chemoprophylaxis & No & $2 \mathrm{C}$ \\
\hline Head and neck free flaps & Chemoprophylaxis & Individualized & $2 \mathrm{C}$ \\
\hline
\end{tabular}

Reproduced from Pannucci et al. [25].

Table 3. Recommendations and GRADE level. 
Head and neck reconstruction using a free flap showed a significant venous thromboembolism risk reduction with chemoprophylaxis but also a significant increase in a composite bleeding endpoint. Bleeding within the neck or adjacent to the airway can be life threatening and thus has a different risk profile than prior recommendations. Surgeons must consider chemoprophylaxis on a case-by-case basis. After an exhaustive review of the existing literature, a consensus recommendation was created and is summarized in Table 3.

The risk of venous thromboembolism in esthetic or reconstructive plastic surgery is real, and complications may range from minor to life threatening. In the setting of elective surgery, all these considerations should be strongly considered and weighed against the potential for postoperative bleeding and secondary monitoring or interventions.

\section{Conclusion}

Given the morbidity and mortality associated with venous thromboembolism and the inaccuracy of screening modalities, prevention should be the goal in this group of patients. We recommend an individualized assessment of risk in each patient and according to the scales presented, determine the individual risks, and the best prophylaxis to be applied before and after the surgery.

\section{Author details}

Alexandro Aguilera Salgado ${ }^{1 *}$, Johnatan Figueroa Padilla ${ }^{2}$ and José Cortés Arreguín ${ }^{3}$

*Address all correspondence to: alexandruss@hotmail.com

1 National Institute of Pediatrics, Mexico City, Mexico

2 National Institute of Cancerology, Mexico City, Mexico

3 Moreno Valle Traumatology and Orthopedics Hospital, Mexico City, Mexico

\section{References}

[1] U.S. Department of Health and Human Services. The Surgeon General's call to action to prevent deep vein thrombosis and pulmonary embolism. 2008. Available at: http:// www.surgeongeneral.gov/topics/deepvein/calltoaction/call-to-action-ondvt-2008.pdf. 
[2] Grazer FM, de Jong RH. Fatal outcomes from liposuction: census survey of cosmetic surgeons. Plast Reconstr Surg. 2000; 105:436.

[3] Clayman MA, Caffee HH. Office surgery safety and the Florida moratoria. Ann Plast Surg. 2006; 56:78.

[4] Albin R, de Campo T. Large-volume liposuction in 181 patients. Aesthetic Plast Surg 1999; 23:5.

[5] Grazer FM, Goldwyn RM. Abdominoplasty assessed by survey, with emphasis on complications. Plast Reconstr Surg. 1977; 59:513.

[6] Aly AS, Cram AE, Chao M, Pang J, McKeon M. Belt lipectomy for circumferential truncal excess: The University of lowa experience. Plast Reconstr Surg. 2003; 111:398.

[7] Broughton G, II, Rios JL, Rohrich RJ, Brown SA. Deep venous thrombosis prophylaxis practice and treatment strategies among plastic surgeons: survey results. Plast Reconstr Surg. 2007; 119:157.

[8] British Thoracic Society Standards of Care Committee Pulmonary Embolism Guideline Development Group. British Thoracic Society guidelines for the management of suspected acute pulmonary embolism. Thorax 2003; 58:470-83.

[9] Anderson FA, Spencer FA. Risk factors for venous thromboembolism. Circulation. 2003; 107:I9-I16.

[10] Seruya M. MOC-PS CME: venous thromboembolism prophylaxis in plastic surgery patients.. Plast Reconstr Surg. September 2008; 122(3), 1701-1708.

[11] Moser KM, Fedullo PF, et al. Frequent asymptomatic pulmonary embolism in patients with deep venous thrombosis. JAMA. 1994; 27:223-225.

[12] Kearon C. Natural history of venous thromboembolism. Circulation. 2003; 107:I22.

[13] McIntyre KM, Sasahara AA. The hemodynamic response to pulmonary embolism in patients without prior cardiopulmonary disease. Am J Cardiol. 1971; 28:288-94.

[14] Bĕlohlávek J, Dytrych V, Linhart A. Pulmonary embolism: epidemiology, risk factors and risk stratification, pathophysiology, clinical presentation, diagnosis and nonthrombotic pulmonary embolism. Exp Clin Cardiol. 2013; 18(2), 129-138.

[15] Poponick, Bosker. The current challenge of venous thromboembolism in the hospitalized patient: Optimizing recognition, evaluation, and prophylaxis of deep venous thrombosis and pulmonary embolism. Part I: Patient identification, risk factor assessment, and diagnostic strategies. Hosp Med Consensus Rep. Available at: www.clinicalconsensusreports.com. Accessed November 28, 2007.

[16] Kucher N, Koo S, Quiroz R, Cooper JM, Paterno MD, Soukonnikov B, Goldhaber SZ. Electronic alerts to prevent venous thromboembolism among hospitalized patients. $\mathrm{N}$ Engl J Med. 2005; 352:969-977. 
[17] Pannucci CJ, Shanks A, Moote MJ, Bahl V, Cederna PS, Naughton NN, Wakefield TW, Henke PK, Campbell DA, Kheterpal S. Identifying patients at high risk for venous thromboembolism requiring treatment after outpatient surgery. Ann Surg. 2012; 255:1093-1099.

[18] Yale SH, Medlin SC, Liang H, Peters T, Glurich I, Mazza JJ. Risk assessment model for venothromboembolism in posthospitalized patients. Int Angiol. 2005; 24:250-254.

[19] Rogers SO, Kilaru RK, Hosokawa P, Henderson WG, Zinner MJ, Khuri SF. Multivariable predictors of postoperative venous thromboembolic events after general and vascular surgery: results from the patient safety in surgery study. J Am Coll Surg. 2007; 204:12111221.

[20] Arcelus JI, Candocia S, Traverso CI, Fabrega F, Caprini JA, Hasty JH. Venous thromboembolism prophylaxis and risk assessment in medical patients. Semin Thromb Hemost. 1991; 17(Suppl 3):313-318.

[21] Pannucci CJ, Bailey SH, Dreszer G, Fisher Wachtman C, Zumsteg JW, Jaber RM, Hamill JB, Hume KM, Rubin JP, Neligan PC, Kalliainen LK, Hoxworth RE, Pusic AL, Wilkins EG. Validation of the Caprini risk assessment model in plastic and reconstructive surgery patients. J Am Coll Surg. 2011; 212:105-112.

[22] Caprini JA. Thrombosis risk assessment as a guide to quality patient care. Dis Mon. $2005 ; 51: 70-78$.

[23] Motykie GD, Zebala LP, Caprini JA, Lee CE, Arcelus JI, Reyna JJ, Cohen EB. A guide to venous thromboembolism risk factor assessment. J Thromb Thrombolysis. 2000; 9:253262.

[24] Caprini JA. Risk assessment as a guide to thrombosis prophylaxis. Curr Opin Pulm Med. 2010; 16:448-452.

[25] Pannucci CJ, MacDonald JK, Ariyan S, Gutowski KA, Kerrigan CL, Kim JY, Chung KC. Benefits and risks of prophylaxis for deep venous thrombosis and pulmonary embolus in plastic surgery: a systematic review and meta-analysis of controlled trials and consensus conference. Plast Reconstr Surg. February 2016; 137(2):709-30.

[26] Gould MK, Garcia DA, Wren SM, Karanicolas PJ, Arcelus JI, Heit JA, Samama CM, American College of Chest Physicians. Prevention of VTE in nonorthopedic surgical patients: antithrombotic therapy and prevention of thrombosis: American College of Chest Physicians Evidence-Based Clinical Practice Guidelines. Chest. 2012; 141(Suppl):e227S-e277S.

[27] Sellam P, Trevidic P. The thromboembolic risk in abdominal plastic surgery: a randomized statistical study. Ann Chir Plast Esthet. 1999; 44:545-548.

[28] Shuman AG, Hu HM, Pannucci CJ, Jackson CR, Bradford CR, Bahl V. Stratifying the risk of venous thromboembolism in otolaryngology. Otolaryngol Head Neck Surg. 2012; 146:719-724. 
[29] Comerota AJ, Stewart GJ, Alburger PD, Smalley K, White JV. Operative venodilation: a previously unsuspected factor in the cause of postoperative deep vein thrombosis. Surgery. 1989; 106:301-308; discussion 308.

[30] Swanson E. Ultrasound screening for deep venous thrombosis detection: a prospective evaluation of 200 plastic surgery outpatients. Plast Reconstr Surg Glob Open. 2015; 3:e332.

[31] Guyatt G, GuttermanD, Baumann MH, et al. Grading strength of recommendations and quality of evidence in clinical guidelines: report from an American College of Chest Physicians task force. Chest. 2006; 129:174-181.

[32] Benkö T, Cooke EA, McNally MA, Mollan RA. Graduated compression stockings: knee length or thigh length. Clin Orthop Relat Res. 2001; 383:197-203.

[33] Sachdeva A, Dalton M, Amaragiri SV, Lees T. Elastic compression stockings for prevention of deep vein thrombosis. Cochrane Database Syst Rev. 2010; 7:CD001484.

[34] Comerota AJ, Chouhan V, Harada RN, et al. The fibrinolytic effects of intermittent pneumatic compression: mechanism of enhanced fibrinolysis. Ann Surg. 1997; 226:306313; discussion 313.

[35] Ho KM, Tan JA. Stratified meta-analysis of intermittent pneumatic compression of the lower limbs to prevent venous thromboembolism in hospitalized patients. Circulation 2013; 128:1003-1020.

[36] Gavriel H, Thompson E, Kleid S, Chan S, Sizeland A. Safety of thromboprophylaxis after oncologic head and neck surgery: study of 1018 patients. Head Neck 2013;35:14101414 .

[37] Bristol Meyers Squibb. U.S. FDA approves Eliquis (apixaban) to reduce the risk of blood clots following hip or knee replacement surgery. March 14, 2014. Available at: http:// news.bms.com/pressrelease/us-fda-approves-eliquis-apixaban-reduce-risk-bloodclots-following-hip-or-knee-replace. Accessed April 27, 2015.

[38] Bayer HealthCare. Rivaroxaban (Web). Available at: www.xareltohcp.com. Accessed April 27, 2015.

[39] Turpie AG, Bauer KA, Caprini JA, Comp PC, Gent M, Muntz JE; Apollo Investigators. Fondaparinux combined with intermittent pneumatic compression vs. intermittent pneumatic compression alone for prevention of venous thromboembolism after abdominal surgery: a randomized, double-blind comparison. J Thromb Haemost. 2007; 5:1854-1861.

[40] Henke PK, Arya S, Pannucci C, et al. Procedure-specific venous thromboembolism prophylaxis: a paradigm from colectomy surgery. Surgery. 2012; 152:528-534; discussion 534 .

[41] Kakkos SK, Caprini JA, Geroulakos G, Nicolaides AN, Stansby GP, Reddy DJ. Combined intermittent pneumatic leg compression and pharmacological prophylaxis for 
prevention of venous thromboembolism in high-risk patients. Cochrane Database Syst Rev. 2008; 4:CD005258.

[42] Kakkos SK, Caprini JA, Geroulakos G, et al. Can combined (mechanical and pharmacological) modalities prevent fatal VTE? Int Angiol. 2011; 30:115-122.

[43] Pannucci CJ, Dreszer G, Wachtman CF, et al. Postoperative enoxaparin prevents symptomatic venous thromboembolism in high-risk plastic surgery patients. Plast Reconstr Surg. 2011; 128:1093-1103.

[44] Davison SP, Massoumi W. Our complication, your problem. Plast Reconstr Surg. 2007; 120:1428-1429.

[45] McDevitt NB. Deep vein thrombosis prophylaxis. American Society of Plastic and Reconstructive Surgeons. Plast Reconstr Surg. 1999; 104:1923-1928.

[46] Akl EA, Kahale L, Sperati F, et al. Low molecular weight heparin versus unfractionated heparin for perioperative thromboprophylaxis in patients with cancer. Cochrane Database Syst Rev. 2014; 6:CD009447.

[47] Hardy RG, Williams L, Dixon JM. Use of enoxaparin results in more haemorrhagic complications after breast surgery than unfractionated heparin. Br J Surg. 2008; 95:834836.

[48] Losken A, Carlson GW, Culbertson JH, et al. Omental free flap reconstruction in complex head and neck deformities. Head Neck. 2002; 24:326-331.

[49] Losken A, Carlson GW, Tyrone JW, et al. The significance of intraabdominal compartment pressure after free versus pedicled TRAM flap breast reconstruction. Plast Reconstr Surg. 2005; 115:261-263.

[50] Pannucci CJ, Alderman AK, Brown SL, Wakefield TW, Wilkins EG. The effect of abdominal wall plication on intraabdominal pressure and lower extremity venous flow: a case report. J Plast Reconstr Aesthet Surg. 2012; 65:392-394. 